\title{
Review Paper on Properties of Properties of Concrete using Steel Fiber Waste
}

\author{
Hitesh Malviya1, Pratiksha Malviya² \\ ${ }^{1}$ M.Tech. Scholar, ${ }^{2}$ Professor \\ Department of Civil Engineering, Millennium Institute of Technology \& Science, \\ Bhopal, Madhya Pradesh, India
}

\begin{abstract}
How to cite this paper: Hitesh Malviya | Pratiksha Malviya "Review Paper on Properties Properties of $\square$ का Concrete using Steel Fiber Waste" Published in International Journal of Trend in Scientific in IITSRD22858 Research and Development (ijtsrd), ISSN: 2456-6470, Volume-3 | Issue-3, April 2019, pp.368-372, URL: http://www.ijtsrd.com/papers/ijtsrd IJTSRD22858.pdf

\section{Copyright (C) 2019} by author(s) and International

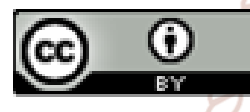
Journal of Trend in Scientific Research and Development Journal. This is an Open Access article distributed under the terms of the Creative Commons Attribution License (CC BY 4.0) (http://creativecommons.org/licenses/ by/4.0)
\end{abstract}

\section{Fiber Reinforced Concrete}

Enhancing the tensile properties of plain concrete numerous strategies have been developed. A considerable lot of the strategies prevailing with regards to making the concrete individuals impervious to strain, however none of them expanded the inborn tractable properties of plain concrete. The scattering of strands in concrete network to enhance its ductile properties has been drilled worldwide more than 3 past decades. The expansion of little firmly separated and consistently scattered filaments to cement would go about as break arrester and would considerably enhance its static and dynamic properties. This sort of concrete is known as fibre reinforced concrete. Fibre strengthened concrete can be characterized as a composite material comprising of blends of bond, mortar, or concrete and broken, discrete, consistently scattered appropriate strands. Consistent lattices, woven textures and long wires or poles are not thought to be discrete fibres.

\section{Fibres Used}

Albeit each kind of fibre has been gone for in cement and concrete, not every one of them can be adequately and monetarily utilized. Each sort of fibre has its trademark properties and constraints. Some of that could be utilized are steel filaments, polypropylene, nylons, asbestos, coir, glass and carbon. Fibre is a little bit of fortifying material having certain trademark properties. They can be round or level. The fibre is regularly portrayed by a helpful parameter called "perspective proportion". The viewpoint proportion of the fibre is the proportion of its length to its distance across. Steel fibre is a standout amongst the most usually utilized filaments. By and large, round filaments are utilized. Polypropylene and nylon strands are observed to be reasonable to build the effect quality. They have high concrete, however their low modulus of versatility and higher prolongation don't add to the flexural quality. Asbestos is a mineral fibre and has ended up being best of all strands as it can be blended with Portland cement. Elasticity of asbestos varies between $560 \mathrm{MPa}$ to $980 \mathrm{MPa}$. The composite item called asbestos cement has impressively higher flexural quality than the Portland cement paste. Fibre reinforced cement is progressively utilized by virtue of the benefits of expanded static and dynamic elasticity, vitality engrossing trademark and better weakness quality. The uniform scattering give all through the solid gives isotropic properties not regular to the traditionally fortified cement. Fibre fortified cement has been attempted on 


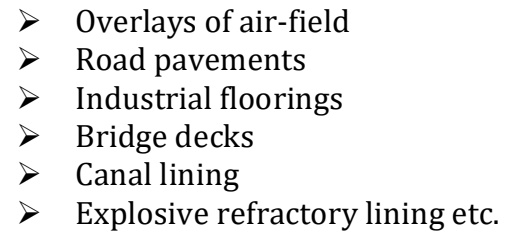

\section{Properties of Fibre Reinforced Concrete}

Fibre reinforced concrete (FRC) is another basic material and it is picking up significance. Expansion of fibre fortification in discrete frame enhances numerous designing properties of cement. Next to no examination work is being led utilizing this new material. This paper depicts the distinctive sorts of strands and the utilization of FRC in various zones. It additionally shows the after-effect of research about the mechanical properties of FRC utilizing straight and in addition snared steel strands accessible in the area. Concrete is feeble in strain and has a fragile character. The idea of utilizing filaments to enhance the qualities of development materials is exceptionally old. Early applications incorporate expansion of straw to mud blocks, horse hair to strengthen mortar and asbestos to fortify earthenware. Utilization of nonstop fortification in concrete (strengthened solid) expands quality and malleability, however requires cautious position and work expertise. On the other hand, presentation of strands in discrete frame in plain or fortified cement may give a superior arrangement. The cutting edge advancement of fiber strengthened cement (FRC) began in the mid sixties. Expansion of filaments to solid makes it a homogeneous and isotropic material. At the point when solid breaks, the haphazardly situated filaments begin working, capture split development and engendering, and in this manner enhance quality and malleability. The disappointment methods of FRC are either bond disappointment amongst fibre or network or material disappointment. In this paper, the Steel Fibre Reinforced Concrete is examined and after-effects of tests done are talked about.

\section{Literature Survey \\ General}

In this section an elaborative talk is made with respect to works done as such far around there as writing audit. Fiber strengthened cement with Steel Fibres craps and their conduct contemplates are talked about in short. Chips away at squander materials are talked about in the consequent headings completely.

\section{Omanakuttan Athira, 2017}

Half breed Fibre-fortified cement is a composite material comprising of blends of bond, fine total, coarse total, steel fibre and glass fibre. The half breed fiber fortified solid displays better weakness quality and expanded static and dynamic rigidity. In this task, the quality of fibre strengthened cement was explored with incomplete supplanting of bond with rice husk slag and fly fiery debris. Steel fibre and glass fibre was included the request of $0.25 \%$, $0.5 \%$ and $0.75 \%$ by volume of concrete and $0.25 \%, 0.5 \%$ and $0.75 \%$ by weight of bond. Rice Husk Ash was utilized to supplant conventional Portland bond by $20 \%$ and fly powder $20 \%$ by weight of concrete extent.

\section{Aswani Sabu and Thomas Paul, 2016}

Fibers are generally used as a common engineering material for crack resistance and strengthening of concrete. Their properties and characteristics greatly influence the properties of concrete which has been proved already in many previous researches. Accordingly it has been found that steel fibers give the maximum strength in comparison to glass and polypropylene fibers. In this experimental study, two types of steel fibers namely hooked end and crimped fibers are used. The volume fractions taken are $0.75 \%, 1.0 \%$ and $1.25 \%$ and M30 grade concrete is adopted. Cement has been replaced with $25 \%$ of Class F flash. The primary focus is to compare the mechanical properties of concrete using both fibres.

\section{R. Madheswaran, S. Arun Singh, K.S. Sathyanarayanan 2014}

Concrete is likely the most broadly utilized development material on the planet. The primary fixing in the regular cement is Portland concrete. The measure of bond generation produces around rise to measure of carbon dioxide into the climate. Concrete creation is devouring noteworthy measure of characteristic assets. That has brought weights to lessen bond utilization by the utilization of supplementary materials. Accessibility of mineral admixtures checked opening of another period for planning solid blend of ever more elevated quality. Fly Ash and silica smolder is another mineral admixture, whose potential isn't completely used. Also just restricted investigations have been completed in India on the utilization of silica smolder for the improvement of high quality cement with expansion of steel strands. The examination centers around the compressive quality execution of the mixed cement containing diverse level of silica smoke and Fly Ash and steel fiber as an incomplete substitution of OPC. The bond in concrete is supplanted as needs be with Silica seethe content was use from $0 \%$ to $10 \%$ in the interim of $2 \%$ in weight premise and furthermore fly cinder content was use from $10 \%$ in weight premise. So to enhance the quality of solid steel filaments were included $0.5 \%, 1 \%, 1.5 \%, 2 \%$ by weight of steel fiber. Solid 3D shapes are tried at the age of 3, 7, and 28 days of curing. At last, the quality execution of Fly slag and silica rage mixed fiber fortified cement is contrasted and the execution of customary cement. From the exploratory examinations, it has been watched that, the ideal substitution Fly fiery remains and silica smoke to bond and steel fiber without changing much the compressive quality is $10 \%$ - $8 \%$ and $1.5 \%$ individually for M25 review Concrete

\section{Hoe Kwan MahyuddinRamli, 2015}

Notwithstanding being presented to chloride and sulfate assaults, marine structures are liable to seismic and affect loads coming about because of waves, affect with strong protests, and water transports. Accordingly, the flexural conduct and effect protection of Fiber-Reinforced Concrete (FRC) in marine condition must be clarified. Nonetheless, such data is barely announced. Along these lines, this examination plans to investigate the impacts of mimicked forceful conditions on flexural quality and effect protection of FRC and to recognize the connection between the two parameters. Three sorts of filaments, specifically, coconut fiber, Barsrap fiber (BF), and soluble base safe glass fiber, were utilized as a part of this investigation. The fiber measurements extended from $0.6 \%$ to $2.4 \%$ of the cover volume. All blends have consistent water/folio proportion of 0.37 and their compressive qualities were all surpassing 60 $\mathrm{MPa}$. The examples were arranged and presented to three diverse forceful presentation situations, in particular, tropical atmosphere, cyclic air and seawater conditions, and seawater condition for up to 180 days. Results demonstrate 
that flexural quality and effect protection of FRC have an immediate association with fiber content. Regardless, change in fiber write is more critical than expanding fiber dose in improving flexural quality yet modification in the two issues would fundamentally affect the effect protection. Rigidity of an individual $\mathrm{BF}(640 \mathrm{MPa})$ is significantly higher than the flexural quality of the BFRC composite. Along these lines, disappointment of solid lattice was seen to happen preceding the crack of the fiber which thusly brought about fiber haul out from the solid grid. Among the different FRC analyzed, FRC containing the most elevated BF content $(2.4 \%)$ exhibited the best flexural quality execution. The flexural quality of the Bar srap FRC was seen to be expanded by $11-13 \%$ in all presentation situations following 180 days. The pre-break vitality ingestions, which were resolved through effect stack test, were found to increment by 60 $63 \%$ when contrasted with the control solid, which showed no post-split vitality assimilation. In the interim, the postbreak vitality retentions of the $2.4 \mathrm{BF}$ were found to go between $3.67 \mathrm{~J}$ and $3.71 \mathrm{~J}$ for different ecological introduction conditions. Examination of fluctuation (ANOVA) comes about demonstrated that flexural qualities were fundamentally expanded following a half year of presentation to the different forceful condition conditions, particularly in seawater. This could be because of arrangement of salt gems which contributed towards improving the fiber/lattice frictional bond. Notwithstanding, the presentation situations have no noteworthy impact on affect protection execution.

\section{Su-Jin Lee, 2014}

In this investigation, basic nano-engineered and steel filaments were utilized to lessen the measure of steel rebar appropriated in precast fortified solid composite individuals. The flexural execution of the individuals was assessed utilizing longitudinal steel proportions of 1.65 and 1.20 and a transverse steel proportion of 0.20 . Cross breed fiber blends comprising of different measures of auxiliary nanomanufactured and snared end steel filaments were utilized as fortifying materials alongside the steel rebar. The nanomanufactured fiber volume parts were $0.4,0.5$, and $0.6 \mathrm{vol}$. $\%$, and the steel fiber substance were 5,10 , and $20 \mathrm{~kg} / \mathrm{m} 3$. Flexural execution tests were completed for the subsequent half breed fiber-strengthened bond composites. The test outcomes exhibited that the half breed fiber-fortified concrete composites fulfilled the essential conditions to supplant the general strengthening bars as per the RILEM standard when the blend contained 0.4 vol. \% of nanomanufactured fiber and $20 \mathrm{~kg} / \mathrm{m} 3$ of steel fiber. The flexural conduct of a $350 * 180 * 1500-\mathrm{mm}$ precast composite part fortified by such a half and half fiber blend and steel rebar was assessed; its most extreme load was 30\% more noteworthy than the outlined extreme load and 3.5\% more prominent than that of a steel fiber-strengthened composite part. The material execution of cement with a half and half blend of fortifying basic nano-engineered and steel filaments was assessed. The best blend was then tried in a precast RC composite part utilizing the most reduced conceivable steel proportion to assess the flexural execution.

6. Lijun Wang, Jing Zhang, Xu Yang, Chun Zhang, 2016 Epoxy syntactic froths containing 15 wt.\% empty glass smaller scale expand were strengthened by fiberglass work as well as short glass fiber, and the flexural conduct of these froths were examined. Flexural tests comes about demonstrated that the nearness of glass fiber or fiberglass work prompted expanded estimations of quality and modulus in syntactic froths contrasted and unreinforced syntactic froths. Furthermore, fiberglass work was observed to be considerably more productive. By adding two-layer fiberglass work to the glass fiber fortified syntactic froths, the flexural quality and modulus additionally expanded just about 2.5 and 2 times, individually, while the thickness of the strengthened froth just expanded by $9.3 \%$. Moreover, it was discovered that the position and layers of fiberglass work had huge impact of the flexural properties. The disappointment modes and instruments of various fortified syntactic froths are inspected and the basic contrasts are talked about. Flexural properties of strengthened syntactic froths are explored in this examination. Fiberglass work and additionally short glass fiber stirred as support to get three arrangement of composites. Results demonstrate that the flexural properties are improved by the nearness of glass fiber or fiberglass work and fiberglass work is observed to be significantly more proficient. The flexural quality and modulus expanded by_28\% and_19\%, individually, for the fiber-fortified syntactic froths as for that of the unreinforced syntactic froths. Be that as it may, the expansion of one-layer fiberglass work created an essential change in flexural quality and modulus (165\%and 38\%, individually) contrasted and unreinforced froth, when the area of the fiberglass work was far from the pressure surface $(\mathrm{x} / \mathrm{h}=1)$. Syntactic froths strengthened by $0.5 \mathrm{wt} \%$ glass fiber and two-layer fiberglass work demonstrated 2.8 and 2.4 times higher flexural quality and modulus than that of the plain syntactic froths while the thickness of fortified froth just expanded by $9.3 \%$. The crack surface demonstrated that the impact of area of work on the flexural properties was because of various disappointment components. Amid flexure, the fiberglass work on the tractable side can stop the small scale breaks engendering while the arbitrarily scattered short glass strands can connect splits at short interims and diminish their spread rate. Hypothetical investigation indicated assist improvement in flexural quality might be accomplished by enhancing the interface bond between fiber work and polymer lattice.

\section{Barzin Mobasher, Yiming Yao (2015)}

Cross breed strengthened cement (HRC) is alluded to as a basic part that consolidates ceaseless support with haphazardly dispersed slashed strands in the network. An explanatory model for predicting Flexural conduct of HRC which is appropriate to regular and fiber strengthened cement (FRC) is exhibited. Conditions to decide the momentebb and flow relationship, extreme minute limit, and least flexural fortification proportion are expressly inferred. Parametric investigations of the impact of residual Tensile quality and support proportion are led and results affirm that the utilization of discrete fibers Increases remaining elasticity and improves minute limit possibly. However enhancements in Post-break firmness and twisting under load is significant in contrast with regular steel support. Quantitative measures of the impact of fiber support on the solidness maintenance and decrease of bend at a given connected minute are gotten. The approach can likewise be displayed in type of a plan Figure, speaking to standardized minute limit as an element of remaining rigidity and support proportion. Numerical reenactments are directed on the steel fiber strengthened cement (SFRC) and HRC shaft tests from distributed writing and the investigative arrangements foresee the test flexural reactions very favorably. Material attributes of HRC are glorified utilizing versatile leftover 
rigidity for strain and versatile splendidly plastic for pressure and a flexible impeccably plastic fortifying steel. Expository answers for unbiased pivot profundity, momentebb and flow, and compelling solidness at each phase of flexural mish opening are acquired. Expository articulations for load-avoidance reaction are unequivocally determined in view of disentangled bilinear moment- shape bends. Parametric investigations exhibit that the utilization of discrete strands to build remaining rigidity isn't as compelling as nonstop fortification in enhancing the minute limit, however the capacity of filaments to circulate breaking prompts higher solidness and quality than plain strengthened cement.

\section{IlkerFatih Kara, Ashraf F. Ashour , Mehmet AlpaslanKorog 2015}

This paper exhibits a numerical technique for evaluating the arch, diversion and minute limit of Hybrid FRP/steel strengthened solid shafts. A sectional investigation is first completed to foresee the moment- ebb and flow relationship from which shaft diversion and minute limit are then computed. In view of the measure of FRP bars, distinctive disappointment modes were recognized, to be specific elastic break of FRP bars and solid smashing previously or subsequent to yielding of steel reinforcement..Comparisons amongst hypothetical and exploratory consequences of tests directed somewhere else demonstrate that the proposed numerical method can precisely foresee minute limit, arch and avoidance of cross breed FRP/steel fortified solid pillars. The numerical outcomes additionally demonstrated that bar malleability and firmness are enhanced when steel fortification is added to FRP strengthened solid bars. A numerical strategy in view of balance of powers and full similarity of strains has been created to assess the momentebb and flow relationship, minute limit and avoidances of half and half FRP/steel fortified solid shafts and steelfortified solid bars reinforced with NSM FRP bars/strips. Correlations between exploratory outcomes accessible in the writing and anticipated arch, minute limit and diversion of cross breed FRP/steel fortified solid bars indicate great agreement. The proposed show likewise gives great outcomes for the minute limit of fortified solid shafts reinforced with NSM FRP bars/strips. The proposed procedure can foresee both the pre and post making avoidances laugh hysterically to the shaft disappointment and to catch the bar conduct in the wake of yielding of steel or burst of FRP fortifications. The Bischoff display for avoidance forecast analyzes well at low load levels when the main splitting burden, in any case, fundamentally thinks little of the trial comes about for high lead levels. A parametric report reasoned that the commitment of steel. Reinforcement to FRP solid shafts gives pliability and firmness change of pillars examined. The FRP fortification was found to assume a vital part to oppose stacking in the wake of yielding of steel in finished strengthened areas. The outcomes additionally showed that cross breed GFRP/steel strengthened solid pillars display a critical diminishment in solidness after the start of first break and yielding of steel fortification in correlation with half and half CFRP/steel solid shafts.

\section{Maher A. Adam 2015}

This paper introduces a trial, numerical and explanatory investigation of the flexural conduct of concrete Beams strengthened with privately delivered glass fiber fortified polymers (GFRP) bars. Glass fiber fortified polymers (GFRP) support bars has a lower solidness than steel fortification, which ought to be represented a definitive and serviceability conditions, including the effect on part diversion and split widths. The bars are privately delivered by twofold incredible utilizing neighborhood assets crude materials. A sum of ten pillars, estimating $120 \mathrm{~mm}$ wide _ $300 \mathrm{~mm}$ profound _ $2800 \mathrm{~mm}$ long, were thrown and tried up to disappointment under four-point bowing. The fundamental parameters were fortification material type(GFRP and steel), concrete compressive quality and support proportion (lb, 1.7 $\mathrm{lb}$ and $2.7 \mathrm{lb}$; whereby is the fortification proportion at adjusted condition). The mid-traverse diversion, break width and GFRP the split widths and mid-traverse avoidance were altogether diminished by expanding the fortification proportion. A definitive load expanded by $47 \%$ and $97 \%$ as the support proportion expanded from $\mathrm{lb}$ to $2.7 \mathrm{lb}$. Examples fortified by $2.7 \mathrm{lb}$ can create some measure of flexibility gave by the solid. The recorded strain of GFRP support came to $90 \%$ of a definitive strains. A non-direct limited component investigation (NLFEA) was built to mimic the flexural conduct of tried shafts, as far as break example and load diversion conduct. It can be viewed as a decent understanding between the test and numerical outcomes was accomplished. Alterations to ACI 440.1R-06 condition for assessing the compelling snapshot of inactivity (Ie) of FRP-fortified solid bars, utilizing relapse investigation of test comes about, is proposed by presenting experimental components that viably diminish the Ie at high load level. The proposed condition is contrasted and diverse code arrangements and past models for foreseeing the redirection. It can demonstrated that the proposed factors gives great estimation for the successful snapshot of dormancy (Ie) functions admirably for FRP-fortified solid pillars at high load level. This examination explored the flexural conduct of solid shafts strengthened with privately created glass fiber fortified polymer (GFRP) bars. Inside the extent of this examination and considering the materials utilized, correlation of the trial comes about with the qualities figured utilizing the proposed condition and other systematic models brought about the accompanying conclusions:.

\section{Problem identification}

$>$ To further evaluate the various experiments have been planned in this research. It has been practiced since ancient times,

$>$ The construction industry is the area where the safe use of steel scraps is possible.

$>$ When it is introduced in concrete as a replacement material, it reduces space problem and also reduces the cost of concrete.

$>$ In industrial plants where Steel Components \& Iron metal products are made, Steel Fiber, is generated in a large quantity as a result of production processes.

$>$ Steel Fiber Waste hinder and control the arrangement of characteristic splitting in solid, subsequently guaranteeing a more strong solid development

\section{Objectives}

The objectives of the research are outlined below:

$>$ The aim project is to have a study comparison between mechanical performances of Steel Fiber reinforced concrete.

$>$ To study the workability of concrete prepared by partial replacement of coarse aggregate using steel fiber. 


\section{CONCLUSION}

Compressive, Tensile and flexural quality is expanding on expanding the level of Steel Fiber Waste and most extreme quality was accomplished on account of $7.5 \%$ Steel Fiber Waste for review of solid M-25.

\section{REFERENCES}

[1] C.Sudha , K. Divya Krishan, P.T Ravichandran and P.R. Kannan Rajkumar, " Strength characteristics of High Strength Concrete using M-sand". Indian Journal of Science and Technology, Vol 9(41), 2016.

[2] Deepthy.S.Nair and Dr. Mathews.M.Paul, "Study on Hybrid Length Steel Fiber Reinforced Concrete Subjected to Elevated Temperatures", International Journal of Engineering Research and Technology, Vol.3, Issue 9, Sep 2014.

[3] Milind. V. Mohod, " Performance of Steel Fiber Reinforced Concrete", Internationl Journal of Engineering and Science, Vol.1, Issue 12 (December 2012), PP 01-04.

[4] Nitin Kumar and Sangeeta , "A Review study on use of Steel Fiber as Reinforcement Material with Concrete", IOSR Journal of Mechanical and Civil Engineering, Vol.12, pp 95-98, 2015.

[5] P. Jaishankar and Vayugundla chenchu Eswara Rao, " Experimental study on the Strength of Concrete by using Metakaolin and M-sand". International Journal of ChemTech Research, Vol.9, No.05 pp 446-452, 2016.
[6] Premalatha and Sudarrajan, "Mechanical Strength Properties, of High Strength Fibrous Added to Concrete", ACI Material Journal,2007.

[7] Sudheer jirobe, Brijbushan S, Maneeth D. "Experimental investigation on strength and durability properties of hybrid fiber reinforced concrete" International Research Journal of Engineering and Technology (IRJET) Volume: 02 Issue: 05, Aug-2015. PP 891- 896.

[8] T. Shanmugapriya and Dr. R.N. Uma, "Strength and Durability Studies on High Performance Concrete With Manufactured Sand as Fine Aggregate". International Journal of Applied Engineering Research, Vol. 10, No. 2 pp 1919-1924, 2015.

[9] Tahmul Hussian, Maneeth P.D, Brij Bhushan S, Rohan S Gourav, Shreenivas Reddy Shahapur, " Experimental Investigation on Strength Characteristics by Partial Replacement of Natural Sand by M-Sand \& Bagasse Ash over Cement for M40 Concrete", International Journal for Scientific Research \& Development (IJSRD)-Vol.4, Issue 6,2016,pp. 380-384.

[10] V.S. Vairagade, KS Kene, T.R Patil “ Comparative Study of Steel Fiber Reinforced Over Control Concrete", International Journal of Scientific and Technology, 2012.

[11] Y.Mohammadi, S.P.Singh and S.K Kaushik, "Properties of Steel Fibrous Concrete Containing Mixed Fibers in Fresh and Hardened State", Construction and Building Materials, May 2008, Vol. 22(5); 956-965. 